\title{
Resources for service provision: policies and politics
}

\author{
Lindsay Edouard
}

International Advisory Editor, Port Louis, Mauritius

Correspondence to Professor Lindsay Edouard; soranae@gmail.com

Received 11 June 2017 Accepted 9 August 2017

\section{Linked}

- http://dx.doi.org/10.1136/ jpprhc-2016-101864

CrossMark

To cite: Edouard L. J Fam Plann Reprod Health Care 2017:43:339-341.

\section{SUMMARY}

Looking back 25 years, this journal reported on the formation of a new Faculty that drew upon the synergy of different professional entities, supporting the British government's priority for sexual health in its new health strategy. International comparisons, with Eastern Europe and America, were valuable for objective reviews of service delivery. Twenty-five years on, in 2017, a rapidly changing political situation in the United States is again threatening global reproductive health.

\section{FAILURES}

Twenty-five years ago, this journal reported on Dr Elphis Christopher's astonishingly prophetic perspective on family planning (FP) in her Jennifer Hallam Memorial Lecture, delivered at the 19th Current Fertility and Reproductive Health Symposium of the National Association of Family Planning Doctors (NAFPD) and the Family Planning Association. ${ }^{1}$ Recalling the court case of 1876 against Annie Besant and Charles Bradlaugh for republishing a pamphlet with its advocacy for contraception, she regretted that despite the favourable environment from subsequent socioeconomic, legal and attitudinal changes, there was still poor utilisation of contraceptive services due to apathy, fatalism and religious convictions.

Dr Christopher stated that the failure of FP services also included unsuccessful management of involuntary infertility, which affected $12 \%$ of couples, the success rate of in vitro fertilisation at that time being only around $15 \%$. Finally, she referred to an increasing trend for couples to elect to be childless: as "abortion of a potential life that cannot be cared for is part of planning a family", services for induced abortion were needed for unwanted pregnancies. ${ }^{1}$

\section{TRANSATLANTIC PERSPECTIVES}

Turning to the USA, Dr Christopher said that the most important donor for international population assistance was a "paradoxical society" and a "complex, wealthy nation with such contradictory public attitudes to sex, contraception and abortion". It needed a bold approach to ignore racist criticism in multicultural settings by using sensitive methods to meet the needs of vulnerable groups. Slogans such as 'Ban the jab' and 'The pill kills' were unfortunate as they adversely affected uptake of hormonal contraception, and the abortion ban resulting from the USA's 'global gag rule' had led to a resurgence in backstreet abortion with its accompanying morbidity and mortality. ${ }^{1}$

The presidency of Ronald Reagan in the 1980s had led to the emergence of a "small but powerful single-issue voting bloc" that was opposed to FP and abortion and that unduly influenced policy formulation and allocation of resources, to the extent that contraceptive services were not usually included in health insurance. ${ }^{2}$ With the gag rule, most American clinics declined federal funding rather than provide inappropriate counselling devoid of any mention of induced abortion.

\section{SITUATION IN ROMANIA}

During her Ann Horler Travelling Fellowship, Katy Shroff had noted that Romanian society "in common with much of Eastern Europe, traditionally regarded induced abortion as a method of birth control". ${ }^{3}$ Dr Christopher pointed out the irony that Bucharest was remembered as the venue of the World Population Conference of 1974, despite the fact that decreasing birth rates had led President Ceausescu to issue the repressive decree of 1966 curtailing contraceptive supplies and abortion services ${ }^{1}$ and promoting at least five children per woman and a tax on infertile couples. ${ }^{3}$ There was an immediate increase in 
maternal mortality due to the rise in illegal abortion, which became the cause of $85 \%$ of maternal deaths. The execution of President Ceausescu and his wife Elena, the "semiliterate" First Lady who had "led on health, science and technology", was announced on Christmas Day of 1989 and on the following day the provisional government had legalised abortion on request during the first 12 weeks of pregnancy. ${ }^{3}$

\section{GLOBAL POSITIONS}

Dr Christopher then turned to issues of overpopulation. Due to possible racist overtones, consideration of population issues in global fora had been a fraught matter until governments started to voice their concerns officially regarding their high population growth rates: contraception immediately came of age, albeit under the cover of FP, which was a useful euphemism to "sweeten the pill" while promoting the benefits of contraception for the health of both mother and child. Addressing the implications of overpopulation for the environment, she expounded upon the increasing responsibility of developing countries for global environmental degradation consequent upon overpopulation. ${ }^{1}$ With the strong relationship between population growth and poverty alongside the complementary roles of "access to family planning and better opportunities for women", ${ }^{4}$ it was reported that Prince Charles was dismayed that population control might be overlooked on the agenda of the imminent Earth Summit. Describing the evolution of the perspective of the Roman Catholic church on FP, including an account of "how the pill had been within a hair's breadth of acceptance by Rome", Dr Nancy Loudon recommended a book as "essential reading for the clergy and policy makers in the developing world" to help individuals "reconcile the teaching of the Church with the realities of their daily lives and moral judgement". 5

\section{NEW FACULTY}

A government White Paper listed sexual health, including FP and HIV/AIDS, as one of five priority areas in the new strategy for health in England, thereby eliminating earlier worries regarding the future of service delivery. ${ }^{6}$ With medical audit becoming increasingly important, relevant NAFPD protocols for FP services were shared with the Royal College of Obstetricians and Gynaecologists (RCOG). ${ }^{78}$ Anticipating a synergistic benefit, both the Joint Committee on Contraception and NAFPD expected a strengthening of their roles through closer collaboration with the RCOG for the formation of a new Faculty: compromises included the inclusion of the phrase 'and Reproductive Health Care' in the title and it was noted that "NAFPD can pass on to the Faculty an established journal and other assets". 910 The specialty of FP would have "more academic respectability" and a career structure, with community gynaecologists "not drawn from the ranks of hospital gynaecology". ${ }^{8}$ However, a rumour among FP doctors of "a takeover bid by the RCOG" unfortunately diverted attention from the opportunity to be seized for "developing the role of community gynaecology for themselves". ${ }^{8}$

\section{CURRENT IMPLICATIONS}

Twenty-five years on, reproductive health has come of age, with its prominence in diverse fora, both national and international. Established on 26 March 1993, the Faculty of Family Planning and Reproductive Health Care (as it was then named) plays a crucial role in representing the profession in the UK, as well as setting standards for training and service delivery that are recognised globally.

Internationally, with their proximity to power, spouses of political leaders from numerous countries have been roped in for advocacy, but the limitations of this approach were evident at the first (and so far only) global First Ladies Summit in Malaysia in 2010. Issues in FP are often controversial as the topics are sensitive for some and compromises are often needed. As with electoral campaigns, all perspectives on service provision deserve respect, as exemplified by services for induced abortion: ${ }^{11}$ utilisation by those expressing a demand for such services should not face hindrance from those who disapprove. Like knowledge, attitudes and practices, clear distinctions should be made between feelings, want, need and demand, ${ }^{12}$ as individuals often change their positions when faced with situations particular to themselves.

An important reason for failure of FP is dissatisfaction of the individual with a contraceptive method that was chosen from the wide range available. Despite the recognised need for new and improved methods, only lip service is often paid to this need by agencies that implement contraceptive service delivery without funding related research and development. Over the last 50 years, the USA has distinguished itself by its strong support of both contraceptive research ${ }^{13}$ and contraceptive service provision in developing countries, but the current tide in its political affairs has unfortunately sometimes led to a disregard of the Sustainable Development Goals. ${ }^{14}$ For effective policy formulation, the Trump administration must heed scientific evidence, but recent reports suggest that senior staff are being appointed who may not follow that obvious course. ${ }^{15}$ Following its decision to withhold budgetary contributions from certain international agencies, the USA might nevertheless pay minimal dues for continuing membership simply in order to maintain an influence in global discussions, especially when those agencies' policies could threaten domestic issues.

Competing interests The author carried out missions on maternal health to Romania for the World Health Organization in 1982 and 1983. 
Provenance and peer review Commissioned; internally peer reviewed.

(C) Faculty of Sexual and Reproductive Healthcare of the Royal College of Obstetricians and Gynaecologists (unless otherwise stated in the text of the article) 2017. All rights reserved. No commercial use is permitted unless otherwise expressly granted.

\section{REFERENCES}

1 Christopher E. Is family planning failing? Br J Fam Plann 1992;18:20-4.

2 Culver MH, Clair J. Family planning in the United States: at the crossroads. Br J Fam Plann 1992;18:1-2.

3 Shroff KJ. From revolution to abortion and contraception in Romania. Br J Fam Plann 1992;18:62-6.

4 Anonymous. News and views - Prince Charles promotes family planning. Br J Fam Plann 1992;18:69.

5 Loudon NB. Review of The Cross of Unknowing: Dilemmas of a Catholic Doctor by Joyce Poole. Br J Fam Plann 1992;18:95.

6 Cayley J. The health of the nation. Br J Fam Plann 1992;18:71-2.

7 Egdell L. Some recipes for audit. Br J Fam Plann 1992;18:59-60.
8 Smith C. From the grass roots. Br J Fam Plann 1992;18:35.

9 Bromham D. Faculty of Family Planning and Reproductive Health Care of the Royal College of Obstetricians and Gynaecologists. Br J Fam Plann 1992;18:33-4.

10 Biddell S. Why do we need a Faculty? Br J Fam Plann 1992;18:35.

11 Maguire DC. Sacred Choices - The Right to Contraception and Abortion in Ten World Religions. Minneapolis, MN: Fortress, 2001.

12 Goldbeck-Wood S. Review of The Moral Case for Abortion.J Fam Plann Reprod Health Care 2017;43:69.

13 Program for Appropriate Technology in Health and United States Agency for International Development. Reinventing the Past to Reshape the Future of Contraception - The Story of the SILCS Diaphragm. Seattle, WA: PATH, 2016.

14 Smith J. On Trump: singular perspectives and the state of global health. Lancet 2017;389:500.

15 Anonymous. Trump set to hand key family planning role to anti-contraception advocate. The Guardian. 2017 https://www. theguardian.com/us-news/2017/may/01/trump-teresa-manningfamily-planning-role (accessed 4 June 2017).

\section{Informative or amusing fillers invited}

Sometimes, in the process of finalising each journal issue for print publication, we are left with blank spaces at the end of artides - like this one. We like to make good use of these spaces when we can, and thus welcome 'fillers' of up to 250 words which inform or entertain.

These fillers can be factual, funny, challenging or creative, but they need to relate to sexual health. Have you come across something wise, informative or amusing on social media which is relavant to our readers? Have you learned something in another field that you think SRH practitioners might benefit from? Have you heard something throughtprovoking in conversation, or have you a haiku up your sleeve?

We cannot guarantee publication, but welcome all ideas and submissions, and will publish these where suitable, and as space in a print journal issue allows. We will let you know if we are unable to publish your contribution for any reason.

All submissions should be submitted to the Journal Editorial Office at Journal@fsrh.org 